\title{
Copper-Lowering Therapy With Tetrathiomolybdate for Cancer and Diseases of Fibrosis and Inflammation
}

\author{
George J. Brewer* \\ Department of Human Genetics and Department of Internal Medicine, University of \\ Michigan Medical School, Ann Arbor, Michigan
}

\begin{abstract}
Angiogenesis is required for tumor growth and is a likely Achilles heel for cancer. However, antiangiogenic agents have been somewhat disappointing in cancer therapy, perhaps because they target a single angiogenic factor, and there is much redundancy in angiogenic systems. Copper is required for high levels of angiogenesis, and many angiogenic factors have a requirement for copper. Thus, anticopper drugs offer the possibility of more global inhibition. Our group has developed tetrathiomolybdate (TM) for the initial treatment of neurologic Wilson's disease. Penicillamine makes about $50 \%$ of these patients neurologically worse, and many never recover. Only 2 of $55(3.6 \%)$ patients worsened when treated with TM. Because TM exhibited desirable properties of potency, speed, and safety, we studied it as an antiangiogenic agent. We hypothesize that if copper is lowered to midrange, the cellular requirements for copper are met, but angiogenic cytokine signaling is inhibited. TM has shown strong inhibition of cancer growth in five rodent models, encouraging results in a canine study of advanced and metastatic cancer, and encouraging results in a phase $1 / 2$ study of advanced and metastatic cancer in 42 patients. Finally, we have hypothesized that the pathway of fibrosis involving transforming growth factor beta (TGF- $\beta$ ) and connective tissue growth factor is inhibitable by copper-lowering therapy with TM. This pathway is overactive and dysregulated in many diseases of fibrosis. In animal studies, TM has completely inhibited the pulmonary fibrosis induced by bleomycin, the hepatitis induced by concanavalin $\mathrm{A}$, and the cirrhosis induced by carbon tetrachloride. We find that TM inhibits transforming growth factor beta and inflammatory cytokines tumor necrosis factor alpha and interleukin-1-beta. J. Trace Elem. Exp. Med. 16:191-199, 2003. @ 2003 Wiley-Liss, Inc.
\end{abstract}

Key words: antiangiogenesis; anticopper drugs; Wilson's disease; cytokines; transforming growth factor beta; tumor necrosis factor alpha

Contract grant sponsor: US Food and Drug Administration's Orphan Products Office; Contract grant numbers: FD-R-000179 and FD-U-000505; Contract grant sponsor: National Institutes of Health; Contract grant number: MO1-RR00042]; Contract grant sponsor: Attenuon LLC, San Diego, CA.

The University of Michigan has recently licensed the antiangiogenic uses of TM to Attenuon LLC, and Dr. Brewer has equity in Attenuon LLC.

*Correspondence to: George Brewer, Department of Human Genetics and Department of Internal Medicine, University of Michigan Medical School, 5024 Kresge Bldg. II, Ann Arbor, MI 48109-0534. E-mail: brewergj@umich.edu

Received 4 February 2003; Accepted 16 July 2003

두 2003 Wiley-Liss, Inc. 


\section{INTRODUCTION}

This work stems from a presentation at the sixth meeting of the International Society for Trace Element Research in Humans held in Quebec City, Canada, September 7-12, 2002. It was the leadoff presentation of a symposium on copper and angiogenesis and in it I gave a brief overview of the topics of angiogenesis and cancer and copper and angiogenesis at the beginning of the session before getting into the research topics of the presentation.

\section{ANGIOGENESIS AND CANCER}

Folkman [1-3] pioneered the concept that tumor growth requires angiogenesis and that this requirement might be an Achilles heel for cancer because in adults there is little requirement for angiogenesis. The concept of antiangiogenic therapy for cancer has taken off in the last decade [4,5], although it is fair to say that results so far have not met previous high expectations, particularly when used as monotherapy [6-8]. A major reason is that angiogenesis has turned out to be a very complex area, with dozens of proangiogenic factors and angiogenic inhibitors potentially interacting [4,9]. It seems likely that therapeutic inhibition of one angiogenic factor or its receptor is simply overcome by the tumor recruiting other factors to overcome the block in angiogenesis produced by the therapy. Thus, current concepts are directed towards finding a global inhibition of angiogenesis produced by the therapy, combining multiple antiangiogenic agents, or combining antiangiogenic therapy with other modalities, such as chemotherapy. This last is based on the logical concept that if tumors are reduced to the smallest possible size by treatment with a modality such as chemotherapy, there is an increased probability that antiangiogenic therapy will prevent regrowth. That is, the fewer the cancer cells remaining, the less likely the cancer will find mutational or other mechanisms for recruiting angiogenic promoters insensitive to the agent being used.

\section{COPPER AND ANGIOGENESIS}

The involvement of copper in angiogenesis has been known for a couple of decades. Copper, or copper-containing molecules, such as ceruloplasmin, when placed in the cornea of the rabbit eye, stimulated angiogenesis [10,11]. If rabbits were made copper deficient with a combination of penicillamine and a lowcopper diet, angiogenic substances placed in the cornea, such as prostaglandin $\mathrm{E}_{2}$, were much less angiogenic [12]. Brem et al. transplanted brain tumors into brains of rats and rabbits and saw much less tumor growth and tumor invasion of normal tissue in copper-deficient animals than in controls [13,14].

\section{ANTICOPPER DRUGS}

The three anticopper drugs that are commercially available are penicillamine, trientine, and zinc. They were all developed as therapies for Wilson's disease, an 
inherited disease of copper accumulation and copper toxicity. Patients with this disease must be on some type of anticopper drug for the rest of their lives to get rid of excess copper and prevent its reaccumutation $[15,16]$.

Penicillamine is the oldest, introduced by Walshe in 1956 [17]. It is a reductive chelator that is quite effective in mobilizing copper and causing large amounts of copper to be excreted in the urine. It is an effective treatment for Wilson's disease but unfortunately has a long list of side effects $[15,16]$. It also has a major disadvantage in that if used in Wilson's disease patients presenting with neurological symptoms, it makes $50 \%$ of them worse, probably by increasing brain copper in the process of mobilizing the large hepatic stores of copper [18]. Half of the patients who worsen, or $25 \%$ of the original sample, never recover to their prepenicillamine baseline; in other words, 1 in 4 of these patients end up with additional, penicillamine-induced, permanent disability.

Trientine was developed by Walshe [19] as a replacement for penicillamine in Wilson's disease patients who were intolerant of penicillamine. It has a similar mechanism of action as penicillamine, acting as a chelator to enhance urinary excretion of copper, but is a much less aggressive drug. It has not been studied very thoroughly, but seems to be generally effective in Wilson's disease. It shares the same toxicities as penicillamine but at a reduced frequency $[15,16]$. I will discuss its use in Wilson's disease below.

Zinc has been developed by my group [15,16,20] and was approved for maintenance use in Wilson's disease by the Food and Drug Administration in 1997. Historically, it was first used by Schouwink in two patients in the Netherlands, but the findings were never published in the general literature [21]. Our use in Wilson's disease was stimulated by our observation that zinc therapy in sickle cell anemia produced copper deficiency as a side effect [22-24]. Zinc acts by inducing intestinal cell metallothionein, which has a high affinity for copper, and blocks copper transfer from the intestine into the blood [25]. The intestinal cells slough with a 6-day turnover time and take the metallothionein copper complex into the stool.

\section{DEVELOPMENT OF TETRATHIOMOLYBDATE FOR WILSON'S DISEASE}

As we worked with zinc to develop it as a maintenance therapy, we became aware, from the histories of our patients, of the problem with penicillamine in making neurologically presenting patients neurologically worse [18]. Thus, penicillamine was contraindicated in these patients. We believe zinc is two slow acting for acutely ill, copper toxic, patients. Trientine had not been tried in these patients, but because it shared penicillamine's mechanism of action, we were concerned that it would precipitate initial worsening.

The lack of a drug for initial therapy led us to develop tetrathiomolybdate (TM) for this purpose [26-29]. TM had, based on animal studies, the appropriate qualities of fast action and lack of toxicity. It had been tried, briefly, as maintenance therapy in Wilson's disease but had been given up because the patients developed anemia [30]. The mechanism of action in TM involves a tripartite complex with protein and copper [31-35]. Given with food, TM forms 
a complex with food protein and copper and prevents copper absorption. Given without food, TM is absorbed into the blood and complexes available copper (potentially toxic copper) with albumin. This copper is unavailable for cellular uptake and is thus nontoxic.

Our first trial was an open study that accrued 55 patients [29]. The design included an 8-week admission to the General Clinical Research Center of the University of Michigan Hospital, during which the patient received $20 \mathrm{mg}$ of TM three times daily with meals and $60-350 \mathrm{mg}$ of TM away from food. The patients were followed with a semiquantitative neurological score $(0-38$, with 0 normal) and a semiquantitative speech score ( $0-7$, with 0 normal). A consistent deterioration of 5 on the neurology score or a deterioration of 2 on the speech score was considered significant deterioration.

Only 2 of the 55 patients reached our criteria, or $3.6 \%$, compared with the roughly $50 \%$ that worsened on penicillamine therapy [29]. Over the next 2 years, during which the patients were on maintenance zinc therapy, they showed substantial neurologic recovery.

We observed two side effects in this study [29]. One was anemia, sometimes accompanied by leukopenia, in six patients. The other was mild further elevation of transaminase enzymes, which occurred in three patients. Both side effects tended to occur more frequently with higher doses or more rapid dose escalation. The anemia/leukopenia is attributed to overtreatment and regional depletion of copper in the bone marrow. The reason for the transaminase elevations is unknown. However, we have not observed it in TM use in cancer patients, so we suspect it is related to an interaction with copper in the copper-loaded livers of these patients. Both side effects respond quickly to a dose reduction or drug holiday.

Because trientine had never been studied for use as initial therapy in neurologically presenting patients and because it is a less aggressive drug than penicillamine, we have conducted a double-blind study comparing the two drugs in this type of patient. This study is almost finished. The design involved 8 weeks of therapy with either $500 \mathrm{mg}$ of trientine twice daily or $20 \mathrm{mg}$ of TM 6 times daily, three of the doses with meals. Both drugs were combined with zinc $50 \mathrm{mg}$ twice daily. The primary measures were the neurologic and speech scores described above, evaluating the frequency of neurologic deterioration. This study is just being finished, but a preliminary examination of the data indicates a deterioration rate with trientine of between 20 and $25 \%$, and confirmation of a low deterioration rate with TM.

In this last study, the frequency of side effects with TM was about $13 \%$ thus far for the anemia/leukopenia and $17 \%$ for the elevated transaminase enzymes. Both side effects responded quickly to halving the dose. We are now initiating a double-blind comparison of $120 \mathrm{mg}$ of TM daily for 8 weeks, the regimen we have been using, to $60 \mathrm{mg}$ of TM daily for 16 weeks, hoping to retain the excellent efficacy and reduce or eliminate the side effects.

Finally, we are evaluating TM for the initial treatment of Wilson's disease patients presenting with hepatic failure, in a double blind, three-arm, comparison with penicillamine and trientine. 


\section{CANCER THERAPY STUDIES WITH TETRATHIOMOLYBDATE}

As we developed TM for Wilson's disease and discovered its excellent properties of anticopper potency, rapid action, and low toxicity, we became interested in evaluating TM as an antiangiogenic anticancer agent based on the copper lowering rationale inhibiting angiogenesis discussed earlier. We first used a mouse model of MCA 205 sarcoma cells, injected subcutaneously into the flank, and demonstrated a significant effect of $\mathrm{TM}$ on slowing growth rate and on decreasing the size of the tumor at sacrifice (Brewer, unpublished data). This led us to team up with an oncologist, Dr. Sofia Merajver, who designed an elegant study using the HER2/neu transgenic mammary cancer genetic model. These mice all develop mammary cancer over the first year of life. Half of the mice were treated with TM, half with vehicle. Over 218 days, 11 of 22 control mice developed obvious tumors, while none of $15 \mathrm{TM}$ mice developed detectable tumors [36]. Release from TM treatment of a few mice resulted in tumor development in all cases. Histologic examination of the breasts of TM treated mice revealed small, avascular, tumor masses.

Our team has gone on to develop positive therapeutic results with TM in four other mouse tumor models [36-39], in a phase 1/2 study of spontaneous advanced and metastatic cancer in pet dogs (Kent, Madewell, and Brewer, unpublished data), and in a phase $1 / 2$ study of advanced and metastatic cancer in human patients [40]. Further details of these studies will be provided in other papers published from this symposium.

\section{ANTIFIBROTIC AND ANTIINFLAMMATORY STUDIES WITH TETRATHIOMOLYBDATE}

The antiangiogenic mechanism of action of TM in cancer appears to involve inhibition of several proangiogenic cytokines and inhibition of nuclear factorkappa $\beta(\mathrm{NF}-\kappa \beta)$, a master switch for many cytokines [36]. The pathway of fibrosis, physiologically important in wound repair and growth and development, consists of a series of cytokines in which transforming growth factor beta (TGF- $\beta$ ) and connective tissue growth factor play key roles. This pathway becomes dysregulated and overactive in diseases of fibrosis involving many organs, such as the lung, liver (cirrhosis), kidney, and skin (scleroderma) [41-47]. In examining the cytokines of this pathway, it seemed likely that the pathway might also be copper dependent. For example, connective tissue growth factor is rich in cysteine, often a tip off of copper binding [45]. One of the activators of TGF- $\beta$ is SPARC (secreted protein acidic and rich in cysteine), already known to be copper dependent [48-50].

To test these ideas, we worked with Dr. Sem Phan, a pathologist at the University of Michigan. We used the bleomycin mouse model. In this model, bleomycin instilled into the trachea produces an inflammatory reaction peaking in 7 days, with tumor necrosis factor alpha (TNF- $\alpha$ ) playing a major role, and leads to extensive pulmonary fibrosis by 21 days, which is when the mice were sacrificed. Fibrosis can be measured by the level of hydroxyproline, a major 
TABLE I. Partial List of Possible Therapeutic Targets of Tetrathiomolybdate Based on Antifibrotic and Antiinflammatory Effects

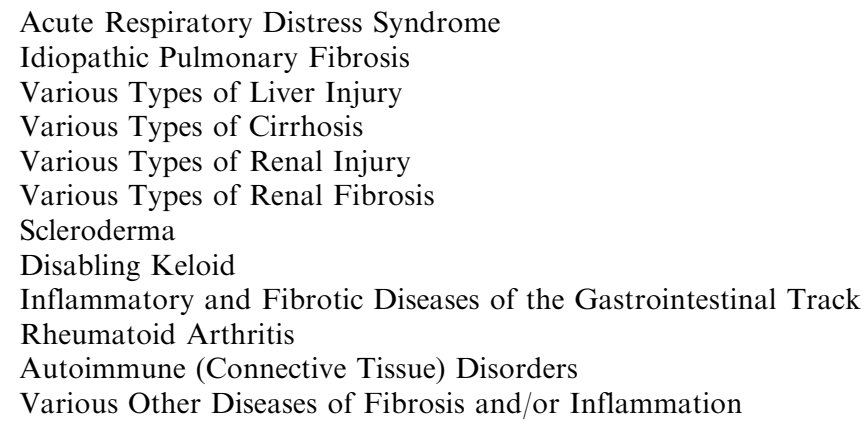

constituent of collagen, in the lung, as well as visualized histologically. The increasing pulmonary fibrosis produces an illness in the mice, easily followed by weight loss.

TM therapy initiated before bleomycin injury completely prevented the fibrosis as measured by hydroxyproline and as seen in histological sections [51,52]. It also completely prevented the illness as evaluated by completely preventing the weight loss from bleomycin injury. At day 7, marked inhibition of TNF- $\alpha$ and TGF- $\beta$ messenger-RNA production by TM was found in mouse lung, as well as a reduction in TGF- $\beta$ protein (Brewer and Phan, unpublished data). Furthermore, TM treatment could be withheld until several days after bleomycin injury, such that copper depletion wouldn't occur until after the 7 days when the inflammatory reactions peaks, and still produce a significant reduction in hydroxyproline levels [52]. The 7-day experiment shows that we are inhibiting inflammation, possibly through inhibition of TNF- $\alpha$. This last experiment shows that we are directly inhibiting fibrosis, not just inhibiting inflammation, which then leads to less fibrosis. We have gone on and in collaboration with Dr. Fred Askari, a hepatologist at the University of Michigan, and shown that we can be similarly successful in inhibiting hepatic injury with TM from either concanavalin A or carbon tetrachloride [53].

We interpret these results in animal model studies to mean that TM may be effective against a large number of fibrotic and inflammatory conditions. A partial list of such therapeutic targets, to exemplify the wide range of possibilities is given in Table I. To begin testing whether the positive animal results carry over to human patients, we are initiating a clinical trial of TM in idiopathic pulmonary fibrosis, with Dr. Kevin Flaherty, a pulmonologist at the University of Michigan, as the principal investigator.

\section{SUMMARY}

Angiogenesis is critical to cancer growth, but antiangiogenic agents as monotherapy targeting specific angiogenic agents or their receptors have not been 
extremely effective as anticancer agents, probably because of the large number of angiogenic promoters, allowing the tumor to take advantage of this redundancy. Anticopper agents have some promise as more global inhibitors of angiogenesis because of the copper dependence of many angiogenic factors. TM as an anticopper agent in animal tumor models looks very effective. In limited patient trials of advanced and metastatic cancer, it has shown encouraging results as sole therapy, but will probably be much more effective in combination with agents, such as chemotherapy, which greatly reduce the tumor burden at the beginning.

TM has shown surprising and dramatic efficacy in lung and liver models of injury which normally produce inflammation and fibrosis. Copper-lowering therapy with TM appears to inhibit inflammatory and fibrotic cytokines which become dysregulated and overactive in a large number of diseases of inflammation and fibrosis. Clinical trials are beginning to see if this aspect of TM efficacy carries over from animals to humans.

\section{ACKNOWLEDGMENTS}

In all of the work described in this article, where data were derived from human patients, the studies were approved by the University of Michigan Institutional Review Board, and informed, written consent was obtained from each patient.

\section{REFERENCES}

1. Folkman J. Tumor angiogenesis: therapeutic implications. N Eng J Med 1971;285:1182-1186.

2. Folkman J. How is blood vessel growth regulated in normal and neoplastic tissue? Cancer Res 1986;46:467-473.

3. Folkman J, Klagsburn M. Angiogenic factors. Science 1987;235:442-447.

4. Brem S. Angiogenesis and cancer control: from concept to therapeutic trial. Cancer Control 1999;6:436-458.

5. Gradishar WJ. An overview of clinical trials involving inhibitors of angiogenesis and their mechanism of action. Invest New Drugs 1997;15:49-59.

6. Susman E. Consensus panel: Antiangiogenesis drugs unlikely as single agents. Oncol Times, June 2001.

7. Susman E. San Antonio Breast cancer symposium. Prediction: Shutting down cancer blood vessels still years away. Oncol Times, April 2002.

8. Dotts T. Is angiogenesis inhibition the future of cancer treatment? Hem/Onc Today March 2002.

9. Beckner ME. Factors promoting tumor angiogenesis. Cancer Invest 1999;17:594-623.

10. Parke A, Battacherjee P, Palmer RM, Lazarus NR. Characterization and quantification of copper sulfate-induced vascularization of the rabbit cornea. Am J Clin Pathol 1988;137: $1121-1142$.

11. Raju KS, Alesandrii G, Zinche M, Gullino PM. Ceruloplasmin, copper ions, and angiogenesis. J Natl Cancer Inst 1982;69:1183-1188.

12. Ziche M, Jones J, Gullino PM. Role of prostaglandin $E_{1}$ and copper in angiogenesis. $\mathbf{J}$ Natl Cancer Inst 1982;69:475-448.

13. Brem SS, Zagzag D, Tsanaclis AMC, Gatley S, Elkouby MP, Brein SE. Inhibition of angiogenesis and tumor growth in the brain. Suppression of endothelial cell turnover by penicillamine and the depletion of copper, an angiogenic cofactor. Am J Pathol 1990;137:1121-1147.

14. Brem S, Tsanaclis AM, Zagzag D. Anticopper treatment inhibits pseudopdial protrusion and invasive spread of 9L gliosarcoma cells in the rat brain. Neurosurgery 1990;26:391-396. 
15. Brewer GJ. Recognition, diagnosis and management of Wilson's disease. Proc Soc Exp Biol Med 2000;223:39-49.

16. Brewer, GJ. Wilson's Disease: a clinician's guide to recognition, diagnosis, and management. Boston: Kluwer Academic Publishers; 2001.

17. Walshe JM. Penicillamine. A new oral therapy for Wilson's disease. Am J Med 1956;21:487-95.

18. Brewer G, Terry C, Aisen A, Hill G. Worsening of neurologic syndrome in patients with Wilson's disease with initial penicillamine therapy. Arch Neurol 1987;44:490-493.

19. Walshe JM. Treatment of Wilson's disease with trientine (triethylene tetramine) dichloride. Lancet 1982;1:643-647.

20. Brewer GJ, Dick RD, Johnson VD, Brunberg JA, Kluin KJ, Fink JK. The Treatment of Wilson's Disease with Zinc XV. Long-Term Follow-up Studies. J Lab Clin Med 1998;132: 264-278.

21. Schouwink G. De hepatocerebrale degeneratie, me een onderzoek naar de zinktofwisseling. University of Amsterdam: MD Thesis 1961.

22. Brewer GJ, Brewer LF, Prasad AS. Suppression of irreversibly sickled erythrocytes by zinc therapy in sickle cell anemia. J Lab Clin Med 1977;90:549-554.

23. Brewer GJ, Schoomaker EB, Leichtman DA, Kruckleberg WC, Brewer LF, Myers N. The uses of pharmacologic doses of zinc in the treatment of sickle cell anemia. In: Brewer GJ, and Prasad AS, editors. Zinc metabolism: current aspects in health and disease. New York: Allan R. Liss, Inc; 1977. p 241-258.

24. Prasad AS, Brewer GJ, Schoomaker EB, Rabbini P. Hypocupremia induced by zinc therapy in adults. JAMA 1978;240:2166-2168.

25. Yuzbasiyan-Gurkan V, Grider A, Nostrant T, Cousins RJ, Brewer GJ. The treatment of Wilson's disease with zinc: X. Intestinal metallothionein induction. J Lab Clin Med 1992;120: 380-386.

26. Brewer GJ, Dick RD, Yuzbasiyan-Gurkan V, Tankanow R, Young AB, Kluin KJ. Initial Therapy of Wilson's Disease patients with Tetrathiomolybdate. Arch Neurol 1991;48:42-47.

27. Brewer GJ, Dick RD, Johnson V, Wang, Yuzbasiyan-Gurkan V, Kluin K, Fink JK, Aisen A. Treatment of Wilson's disease with tetrathiomolybdate I. Initial therapy in 17 neurologically affected patients. Arch Neurol 1994;51:545-554.

28. Brewer GJ, Johnson V, Dick RD, Kluin KJ, Fink JK, Brunberg JA: Treatment of Wilson's disease with ammonium tetrathiomolybdate: II. Initial therapy in 33 neurologically affected patients and follow-up on zinc therapy. Arch Neurol 1996;53:1017-1025.

29. Brewer GJ, Hedera P, Kluin KJ, Carlson MD, Askari F, Dick RB, Sitterly JA; Fink JK. Treatment of Wilson's disease with tetrathiomolybdate III. Initial therapy in a total of 55 neurologically affected patients and follow-up with zinc therapy. Arch Neurol 2003;60: $378-385$.

30. Harper PI, Walshe JM. Reversible pancytopenia secondary to treatment with tetrathiomolybdate. Br J Haematol 1986;64:851-853.

31. McQuaid A, Mason J. A comparison of the effects of penicillamine, trientine, and trithiomolybdate on [35S]-labeled metallothionein in vitro: the implications for Wilson's disease therapy. J Inorg Biochem 1991;41:87-92.

32. Mills CF, El-Gallad TT, Bremner I. Effects of molybdate, sulfide, and tetrathiomolybdate on copper metabolism in rats. J Inorgan Biochem 1981;14:189-207.

33. Bremner I, Mills CF, Young BW. Copper metabolism in rats given di- or trithiomolybdates. J Inorgan Biochem 1982;16:109-119.

34. Mills CF, El-Gallad TT, Bremner I, et al. Copper and molybdenum absorption by rats given ammonium tetrathiomolybdate. J Inorgan Biochem 1981;14:163-175.

35. Gooneratne SR, Howell JM, Gawthorne JM. An investigation of the effects of intravenous administration of thiomolybdate on copper metabolism in chronic $\mathrm{Cu}$-poisoned sheep. $\mathrm{Br} \mathbf{J}$ Nutr 1981;46:469-480.

36. Pan Q, Kleer C, van Golen K, Irani J, Bottema K, Bias C, De Carvalho M, Mesri E, Robins D, Dick R, et al. Copper deficiency induced by tetrathiomolybdate suppresses tumor growth and angiogenesis. Cancer Res 2002;62:4854-4859.

37. Cox C, Teknos T, Barrios M, Brewer G, Dick R, Merajver S. The role of copper suppression as an antiangiogenic strategy in head and neck squamous cell carcinoma. Laryngoscope 2001; 111:696-701. 
38. Khan M, Miller M, Taylor J, Navkiranjit K, Dick R, van Golen K, Brewer G, Merajver S. Radiotherapy and antiangiogenic TM in lung cancer. Neoplasia 2002;4:7.

39. van Golen K, Bao L, Brewer G, Pienta K, Karadt J, Livant D, Merajver S. Suppression of tumor recurrence and metastasis by a combination of the PHSCN sequence and the antiangiogenic compound tetrathiomolybdate in prostate carcinoma. Neoplasia 2002;4:373-379.

40. Brewer G, Dick R, Grover D, LeClaire V, Tseng M, Wicha M, Pienta K, Redman B, Thierry J, Sondak V, et al. Treatment of metastatic cancer with tetrathiomolybdate, an anticopper, antiangiogenic agent: Phase I study. Clin Cancer Res 2000;6:1-10.

41. Khalil N, Greenberg AH. The role of TGF-beta in pulmonary fibrosis. Ciba Found Symp 1991;157:194-211.

42. Border WA, Noble NA. Mechanisms of disease: transforming growth factor (Beta) in tissue fibrosis. N Engl J Med 1994;331:1286-1292.

43. Denis M. Neutralization of transforming growth factor-beta 1 in a mouse model of immuneinduced lung fibrosis. Immunology 1994;82:584-590.

44. Lasky JA, Ortiz LA, Tonthat B, Hoyle GW, Corti M, Athas G, et al. Connective tissue growth factor mRNA expression is unregulated in bleomycin-induced lung fibrosis. Am Physiol Soc 1998;L365-L371.

45. Brigstock DR. The Connective tissue growth factor/cysteine-rich 61/nephroblastoma overexpressed (CCN) family. Endocr Rev 1999;20:189-206.

46. Allen JT, Knight RA, Bloor CA, Spiteri MA. Enhanced insulin-like growth factor binding protein-related protein 2 (connective tissue growth factor); Expression in patients with idiopathic pulmonary fibrosis and pulmonary sarcoidosis. Am J Respir Cell Mol Biol 1999; 21:693-700.

47. Pittet JF, Griffiths MJD, Geiser T, Kaminski N, Dalton SL, Huang X, et al. TGF- $\beta$ is critical mediator of acute lung injury. J Clin Invest 2001;107:1537-1544.

48. Francki A, Bradshaw AD, Bassuk JA, Howe CC, Couser WG, Sage EH. SPARC regulates the expression of collagen type I and transforming growth factor- $\beta 1$ in mesangial cells. J Leukoc Biol 1999;22:32145-32152.

49. Strandjord TP, Madtes DK, Weiss DJ, Sage EH. Collagen accumulation is decreased in SPARC-null mice with bleomycin-induced pulmonary fibrosis. Am Physiol Soc 1999;L628L635.

50. Lane TF, Iruela-Arispe ML, Johnson RS, Sage EH. SPARC is a source of copper-binding peptides that stimulate angiogenesis. J Cell Biol 1994;125:929-943.

51. Brewer G, Phan S. Tetrathiomolybdate anticopper therapy protects against bleomycin-pulmonary fibrosis in mice. J Invest Med 2002;50:227A.

52. Brewer GJ, Ullenbruch MR, Dick R, Olivarez L, Phan SH. Tetrathiomolybdate therapy protects against bleomycin-pulmonary fibrosis in mice. J Lab Clin Med 2003;141:210-216.

53. Askari F, Brewer G. Tetrathiomolybdate anticopper therapy protects against concanavalin A liver damage in mice. J Invest Med 2002;50:220A. 